\title{
Adverse Impacts of Social Networking Sites on Academic Result: Investigation, Cause Identification and Solution
}

\author{
Maruf Ahmed Tamal ${ }^{1}$, Maharunnasha Antora ${ }^{2}$ \\ Md. Abdul Aziz ${ }^{4}$ Pabel Miah ${ }^{5}$ \\ Department of Computer Science \& Engineering \\ Daffodil International University, Dhaka, Bangladesh
}

\author{
Karim Mohammed Rezaul ${ }^{3}$ \\ Faculty of Arts, Science \& Technology \\ Wrexham Glyndŵr University \\ Wrexham, UK
}

\begin{abstract}
Social networking sites (SNS) have become more prevalent over the previous decade. Interactive design and addictive characteristics have made SNS an almost indispensable part of life, particularly among university learners. Previous studies have shown that excessive use of SNS adversely affects learners' academic success as well as mental health. However, still now, there is a lack of clear evidence of the actual rationalization behind these adverse effects. Concurrently, any significant preventive measures are not yet introduced to counter the excessive use of SNS, particularly for students. To bridge this gap, considering a view of 1862 students $($ male $=1183$, female $=$ 659), the current study investigates how and in which way spending time in SNS negatively influences students' academic performance. Correlation and regression analyses showed that there is a powerful negative correlation between students' spending time in social media (STISM) and their educational outcome. Simultaneously, our investigation indicates that classroom standing social media use and late night social media use result in poor educational outcome of the students. Based on the findings of the investigation, an Android based application framework called SMT (Social Media Tracker) is designed and partially implemented to minimize the engagement between students and SNS.
\end{abstract}

Keywords-Social networking sites; SNS; social media; SM; addiction; mental health; poor academic outcome; sleep disorder; social media tracker introduction

\section{INTRODUCTION}

Social media has now become one of the most important channels of communication. It allows people to connect far and near. Over the previous decade, the popularity of social networking sites like Facebook, WhatsApp, WeChat, Instagram, Twitter, etc. has risen rapidly. This is very likely because it is widely used by college, university and youth pupils to access the world's network. According to Statista [1], in the first quarter of 2019, Facebook had 2.38 billion monthly active users. Twitter had more than 330 million monthly active users worldwide as of the first quarter of 2019 [2]. On the other hand, WhatsApp had more than 500 million monthly active users worldwide as of the first quarter of 2019 [3]. Simultaneously, video games also have become a popular way of virtual communication. This clearly indicates that Social Networking Sites are rapidly getting popular. A large proportion of total users of social media are students and it is exponentially growing day by day. There is no doubt that social media has many beneficial effects. At the same time, today, particularly in students, adverse effects are becoming greater. Social media's dark side involves decreasing academic achievement $[4,5]$, increasing anxiety [6], cyberbullying [7, 8], addictive behaviour [9], deprivation of sleep [10], sexting [11] and much more, which are major concerns. It is obvious that Social Medias are designed to be addictive as much as possible for financial gain. According to [12], for economic gain, social media businesses intentionally addict consumers to their products. Most of the social media companies hire 'attention engineers' because they want to make sure that their users give as much as time on their sites and they always try to make their product as addictive as possible. As a consequence, individuals in social media are unconsciously wasting a lot of time. The main problem is that students are also using and becoming addicted to social media. Spending enormous time in social media is affecting their academic performance negatively. At the same moment, excessive use of social media creates various health issues such as poorer sleep quality, anxiety, loneliness, and less self-esteem. However, still now, there is a lack of clear evidence of the actual rationalization behind adverse effects of social media. On the other hand, any significant preventive measures are not yet introduced to counter the excessive use of SNS. The purpose of the study is to find out how social media adversely impacts on student's academic result and introduce the effective preventive measures to minimize the negative effects. However, the following specific objectives have been pursued in order to achieve the main goal of this paper:

1) Finding out the correlation between STISM and student's academic outcome (SGPA) and exploring the intensity of this connection.

2) Exploring, how STISM numerically predicts SGPA of students.

3) Investigating on how social media influence male and female students in everyday life.

4) Finding effective solutions against the adverse effects of social media and develop an android based application to minimize the engagement between students and SNS. 


\section{LITERATURE REVIEW}

In order to attain sustainable education, SM (Social Media) currently plays an indispensable role in the learning behavior of university learners [13]. Globally, SM's use is growing. SM's effect on sustainable education is becoming an important and driving factor. It has undoubtedly become a significant means of communication for learners, especially at the stage of higher education. Connecting and communicating through SNS is now one of the most significant characteristics in the life of college learners. Texting, graphical messaging, sharing, and viewing academic and non-academic things may influence the academic lives of learners, particularly their academic performance [14]. Social media has so many beneficial effects on education. As well as multiple dark sides have become a matter of huge concern, particularly for learners at tertiary level. Most of the time students use social media for entertainment, sharing thoughts with friends. In this way they use social media for non-academic purpose rather than academic purpose. According to [4], the use of social media for educational reasons was not an important predictor of academic performance, while the use of social media for nonacademic reasons and social media multitasking considerably anticipated to be poor academic performance. Students are concurrently engaged in various tasks and while studying and attending school, they are writing, reading and using social media which contributes to obtaining their lower GPA [15]. In [5], the research reveals that time spent on Facebook was considered to be negative for freshmen. But why does nonacademic uses of social media have a negative impact on the student's academic outcome? According to [16], during class session social media uses have a direct and adverse effect on the academic achievement of the student. This distracts learners to focus on the class lessons. The use of social media in classrooms frequently decreases attention towards the quality of lectures which leads to missing lesson information and damaging academic effectiveness. On the other side, the addictive use of social media is associated with reduced selfesteem, anxiety, depression, and bad quality of sleep that adversely affects the academic outcome. According to [17], adolescents who use more social media both in general and at night and those who are more emotionally attached in social media experienced poorer quality of sleep, reduced selfesteem, and greater rates of anxiety and depression. The use of social media over 2 hours per day is linked to bad mental health self-rating and feelings of elevated psychological distress and suicidal ideation [18]. But question is why social media is addictive? Why do individuals spend time there? Probably the answer is dopamine. Dopamine is produced deep in the midbrain and released throughout the brain in many separate fields. These regions are mainly accountable for learning, habit-forming, and addiction-related behaviors [19]. According to [20], dopamine is a neurochemical that is produced in different areas of the brain and is critical in all kinds of brain activities. It improves overall excitement and goal-driven behavior. Ex-Facebook VP of user growth said that Social media (Facebook) promotes short-term dopamine drivers feedback loops which are destroying the society [21]. Another past study [22] revealed that results on social media users from neurological and psychiatric exams indicate that comparable biological and psychological symptoms of alcohol, cigarette and drug addicts are seen in active social media users. In Internet addicts, there are some frequent symptoms shown such as depression, death and suicidal ideas, low self-esteem, loneliness and social isolation (see Table VII). Most of the previous studies have discussed the negative aspects of social media overuse but did not discuss in depth whether and how it has a negative impact on the academic performance of students. At the same time no significant action has been taken to mitigate this issue, particularly for students. A few android-based applications have been identified that can be used to mitigate this issue, but none of them were designed for students in particular (see Table VI).

\section{RESEARCH METHODOLOGY}

The primary purpose of the present study is to explore how excessive use of social media negatively impacts on students' academic performance at university level. As well as develop an android based application to minimize the engagement between students and SNS. To present the overall study, the methodological portion has been split into several sections.

\section{A. Primary and Secondary Data}

A substantial literature review was performed at the beginning of the study to identify the gap in the existing studies. Simultaneously, significant study issues were found through literature review which assisted to collect relevant data. This study was conducted between July 2018 and June 2019 at Daffodil International University, Dhaka, Bangladesh. Primary data was collected through both field survey and online survey. A web-based questionnaire (Google form) was sent to the students' school e-mail addresses with information about the study and survey paper (offline) were distributed to undergraduate students during class time to participate.

\section{B. Measures and Participants}

Five multiple-choice questions along with two general questions where respondents had to input number (SGPA and Spending time in social media), were included in the survey questionnaires. In order to fulfill the research objective and achieve the effective outcome, the following questionnaires were asked to participants "How much time you spend in social media in average?", "What was your SGPA (Semester Grade Point Average) in previous semester", "Do you think social media has positive impact on your academic result?", "Do you ever used social media in classroom?", "When you spend "most of the time" in social media?" and "When you use social media for academic purposes?". A total of 3500 questionnaires were distributed and 1842 valid responses were gathered (field survey: 1267 internet survey: 595), including spontaneous female $(35.8 \%)$ and male $(64.2 \%)$ participants. The ethical factors of the respondent have been closely assured to keep their privacy strictly and confidentially secret. The school administration also approved the ethical permission.

\section{Data Preprocesing}

In order to obtain the precise value, dataset was fully prepossessed until irrelevant, incomplete, inconsistent information were removed. Several python libraries were used to preprocess the raw data. To discover outliers we used box 
plot and Interquartile Range (IQR) measures as a part of data preprocessing. A boxplot is a graph that provides a good idea of how the information values are distributed. It is a standardized way to display information of distribution. Simultaneously, IQR says how the "center" values are spread out; it can also be used to say when some of the other values are "too far" from the main value. These points "too far" are called "outliers," As outliers negatively influence actual findings, we removed all outliers.

\section{Data Analysis}

a) Correlation Analysis: 4 correlation statistics (Spearman, Pearson r, Kendalltau and Point Biserial) were followed to assess the strength and direction (either positive or negative) of the relationship between two factors (Spending time in social media (STISM) and Semester Grade Point Average (SGPA)). The value of the correlation coefficient differs between +1 and -1 in terms of the intensity of the connection. A value of \pm 1 refers to an ideal degree of connection between the two variables. The connection will be weaker as the correlation coefficient value goes close to 0 . The sign of the coefficient shows the direction of the relationship; + sign shows a positive connection and - sign indicates a negative connection.

b) Regression Analysis: The correlation only determines the relationship between two factors and reflects the linear relationship. But regression depicts the numerical relationship between an independent variable and the dependent variable. As we also required to understand how STISM affects SGPA, we used linear regression determining STISM as an independent variable and SGPA as a dependent variable.

\section{DESCRIPTIVE ANALYSIS}

\section{A. Respondents based on Gender}

3,500 survey questionnaires had been distributed to collect the primary data, over the university students. Total 1918 responses were collected and preprocessed. After removing the irrelevant, incomplete, inconsistent records, 1842 records were selected for analysis. Table I shows the frequency distribution and percentage of students according to gender. There was a spontaneous response from both male and female participants. The proportion of participants among male and female were $64.2 \%$ and $35.8 \%$, respectively where the participants ' age ranged from 19 to 25 .

\section{B. Use of Social Media Affecting Academic Grade}

The application of social media has become a prevalent phenomenon among all age groups. This is more common among adolescents and young adults. It is evident that students using social media for a longer period of time adversely affect academic achievement. Table II demonstrates a descriptive summary of academic grades achieved by students and corresponding spending time in social media. At the same time, it shows that the students who are good in terms of academic results spent less time on social media. On the other hand, students spending an enormous amount of time on social media have obtained poor academic results. For male students who achieved A+ (SGPA) and A (SGPA), they used Social Media (SM) for 2.19 hours and 2.02 hours respectively. On the other hand, the majority of them performed poor grades (e.g. C and D) when they spent a longer period of time in SM (e.g. 7.43 and 8.18 hours). Like the male, female also showed the same tendency. Those female students achieved good academic results (e.g. A+, A, A-, B+) spent less amount of time in social media. At the same time, female students with the poor academic result $(\mathrm{C}+, \mathrm{C}, \mathrm{D})$ spent a longer amount of time on social media.

TABLE. I. FREQUENCY DisTRIBUTION ACCORDING TO SEX

\begin{tabular}{|l|l|l|}
\hline Gender & Frequency & Frequency distribution in percentage \\
\hline Male & 1183 & $64.2 \%$ \\
\hline Female & 659 & $35.8 \%$ \\
\hline
\end{tabular}

TABLE. II. DESCRIPTIVE STATISTICS OF STISM* ACCORDING TO GRADE

\begin{tabular}{|c|c|c|c|c|c|c|}
\hline \multirow{3}{*}{ Grade } & \multicolumn{6}{|c|}{ Spending time in social media } \\
\hline & \multicolumn{3}{|c|}{ Male } & \multicolumn{3}{|c|}{ Female } \\
\hline & $\mathrm{N}$ & $\begin{array}{l}\text { Mean } \\
\text { (Hour) }\end{array}$ & SD & $\mathrm{N}$ & $\begin{array}{l}\text { Mean } \\
\text { (Hour) }\end{array}$ & SD \\
\hline$A+$ & 70 & 2.193 & 2.022 & 56 & 1.651 & 1.147 \\
\hline A & 201 & 2.019 & 1.492 & 186 & 2.375 & 1.914 \\
\hline A- & 184 & 3.587 & 1.492 & 101 & 3.292 & 1.666 \\
\hline $\mathrm{B}+$ & 211 & 4.367 & 1.576 & 104 & 4.361 & 1.816 \\
\hline B & 185 & 5.051 & 1.891 & 100 & 5.450 & 1.919 \\
\hline B- & 136 & 7.526 & 2.037 & 69 & 7.623 & 2.201 \\
\hline $\mathrm{C}+$ & 59 & 7.508 & 2.575 & 53 & 8.122 & 1.715 \\
\hline $\mathrm{C}$ & 61 & 7.434 & 2.169 & 18 & 7.361 & 1.473 \\
\hline $\mathrm{D}$ & 70 & 8.182 & 2.793 & 27 & 8.425 & 2.567 \\
\hline
\end{tabular}

\section{Relationship between Spending Time in Social Media (STISM) and Semester Grade Point Average (SGPA)}

Addictive use of social media wastes a lot of time that adversely affects the educational outcome of students. To evaluate the correlation between STISM and SGPA, we performed 4 distinct correlation statistics (Spearman, Pearson r, Kendalltau, and Point Biserial). Simultaneously regression analysis was performed to demonstrate how SGPA is numerically related to the STISM. According to the findings of the correlation analysis (see Table III and Table IV), it is shown that STISM and SGPA are highly negatively correlated both for males and females. For male, the correlation coefficients are Spearman $=-0.747$, Pearson $r=-0.720$, Kendalltau $=-0.595$ and Point Biserial $=-0.720$. Simultaneously, for female the correlation coefficients are Spearman $=-0.787$, Pearson $r=-0.751$, Kendalltau $=-0.635$ and Point Biserial $=-0.751$.

Regression analysis (see Table III, Table IV, Fig. 1 and Fig. 2) also represents that as an independent factor STISM negatively impacts dependent factor SGPA. For males, the slope of the regression line is $\mathrm{b} 1=-0.140, \mathrm{R}$ square is 0.519 , Adjusted R Square is 0.518 and for females, the slope of the regression line is $\mathrm{b} 1=-0.135, \mathrm{R}$ square is 0.563 , Adjusted $\mathrm{R}$ Square is 0.5626 . 
TABLE. III. REGRESSION AND CORRELATION ANALYSIS BETWEEN STISM AND SGPA: MALE

\begin{tabular}{|c|c|c|c|c|c|c|c|c|c|c|}
\hline \multicolumn{11}{|l|}{ Male } \\
\hline \multirow[b]{2}{*}{$\mathrm{N}$} & \multicolumn{4}{|c|}{ Correlation } & \multicolumn{6}{|c|}{ Regression } \\
\hline & Spearman & Pearson $r$ & Kendalltau & $\begin{array}{l}\text { Point- } \\
\text { Biserial }\end{array}$ & $\mathrm{b}_{0}$ & $\mathrm{~b}_{1}$ & Multiple R & R Square & $\begin{array}{l}\text { Adjusted R } \\
\text { Square }\end{array}$ & $\begin{array}{l}\text { Std. } \\
\text { error }\end{array}$ \\
\hline 1183 & -0.747 & -0.720 & -0.595 & -0.720 & 3.93 & -0.140 & 0.720 & 0.519 & 0.518 & 0.378 \\
\hline
\end{tabular}

TABLE. IV. REGRESSION AND CORRELATION ANALYSIS BETWEEN STISM AND SGPA: FEMALE

\begin{tabular}{|l|l|l|l|l|l|l|l|l|l|l|}
\hline \multicolumn{2}{|l|}{ Female } \\
\hline \multirow{3}{*}{$\mathrm{N}$} & \multicolumn{3}{|l|}{ Correlation } & \multicolumn{2}{l|}{ Regression } \\
\cline { 2 - 11 } & $\begin{array}{l}\text { Point- } \\
\text { Biserial }\end{array}$ & Spearman & Pearson $\mathrm{r}$ & Kendalltau & $\mathrm{b}_{0}$ & $\mathrm{~b}_{1}$ & $\begin{array}{l}\text { Multiple } \\
\mathrm{R}\end{array}$ & $\begin{array}{l}\mathrm{R} \\
\text { Square }\end{array}$ & $\begin{array}{l}\text { Adjusted } \\
\mathrm{R} \text { Square }\end{array}$ & $\begin{array}{l}\text { Std. } \\
\text { error }\end{array}$ \\
\hline 659 & -0.751 & -0.787 & -0.751 & -0.635 & 3.93 & -0.135 & 0.750 & 0.563 & 0.5626 & 0.342 \\
\hline
\end{tabular}

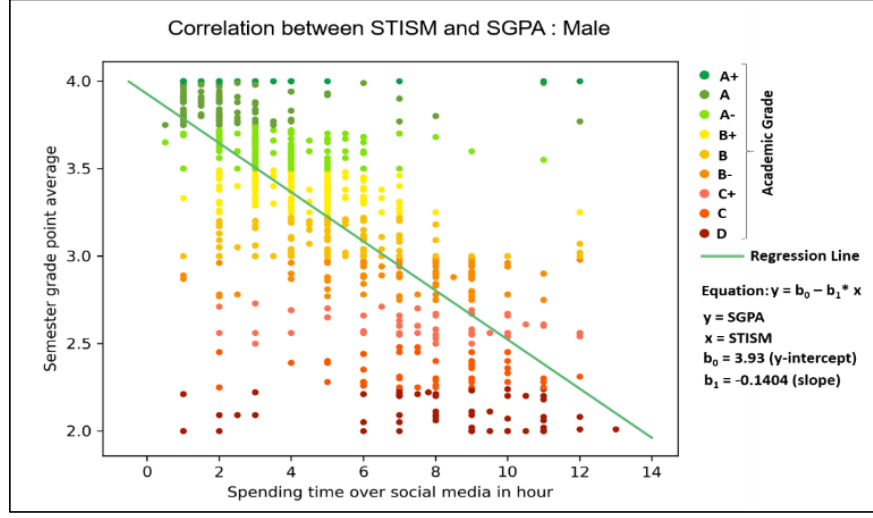

Fig. 1. Correlation between STISM and SGPA (Male)

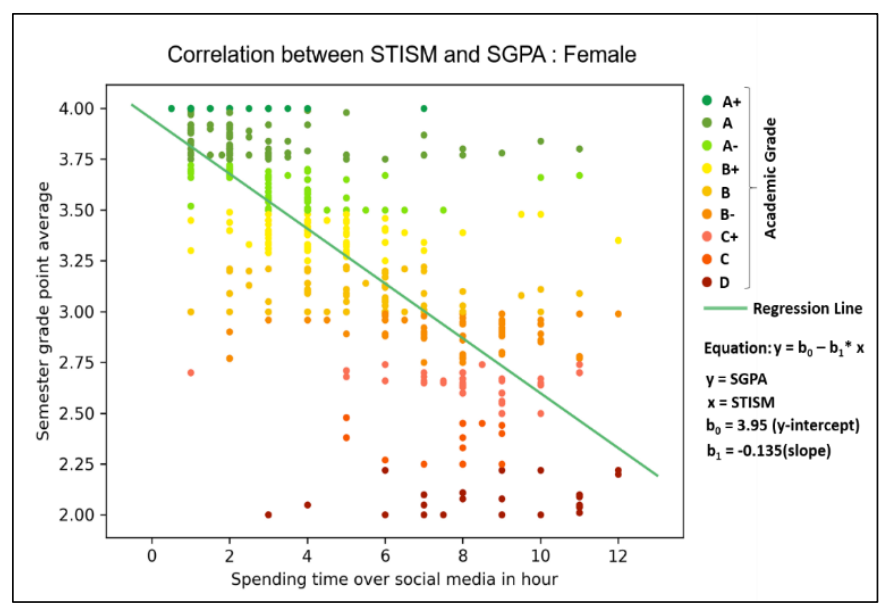

Fig. 2. Correlation between STISM and SGPA (Female).

\section{Using Social Media During Class Time}

The use of social media during class time can be distracting, especially when students use their phones to check Facebook, Twitter, Snapchat, YouTube, Instagram or any other social platforms. As a consequence, their concentration diverts to non-academic operations instead of concentrating on the lesson. We questioned students whether they were using social media in the classroom. About 35.05 percent of students said they used social media in classrooms and 64.95 percent said they didn't use social media in classrooms. We further explored the relationship between classroom-standing social media use and the educational outcome of the student. The result from observation shows in Table $\mathrm{V}$ that students who used social media in the classroom, their educational outcomes were relatively worse than those who did not use it during school time. More specifically from Table V, it can be concluded that students both male and female who did not use social media during class time achieved higher grades such as $\mathrm{A}+, \mathrm{A}, \mathrm{A}-, \mathrm{B}+$.

\section{E. Social Media for Academic Purpose}

Social media provides numerous possibilities for rapid and effective communication with academia. It enables students to interact among themselves both for academic and nonacademic purposes. However, we attempted to figure out the length of engagement in social media for academic purposes. Fig. 3 shows that the majority of the students (42\%) use social media for academic purposes before the exam. The research also reveals that $26 \%$ of students use social media every day and $32 \%$ use every week for educational purposes. So, it is clear that the majority of the students use social media as a tool for entertainment rather than academic purposes. We questioned the students whether they believe that social media positively affects their academic outcome. In response to this question, $43.55 \%$ replied that the use of social media did not result in a positive effect. As well as $29.72 \%$ of students thought that social media caused a positive effect on their educational outcome and $26.73 \%$ said that it had both positive and negative effects on their academic outcome.

\section{F. Student's most Preferred time in Getting Engaged at Social Media}

The use of social media is associated with significant sleep-related results such as a smaller amount of nighttime sleep hours that leads to poorer quality of sleep. We asked students when they prefer spending most of their time on social media. $40.67 \%$ female and $45.48 \%$ male students replied that they spend most of their time in social media at late night (see Fig. 4). 
TABLE. V. Use of Social Media During Class Time

\begin{tabular}{|c|c|c|c|c|c|c|}
\hline \multicolumn{7}{|c|}{ Do you frequently use social media during class time? } \\
\hline \multirow{2}{*}{ Grade } & \multicolumn{3}{|c|}{ Male } & \multicolumn{3}{|c|}{ Female } \\
\hline & $\mathrm{N}$ & Yes & No & $\mathrm{N}$ & Yes & No \\
\hline A+ & 70 & $10.0 \%$ & $90.0 \%$ & 56 & $17.9 \%$ & $82.1 \%$ \\
\hline A & 201 & $15.4 \%$ & $84.6 \%$ & 130 & $21.5 \%$ & $78.5 \%$ \\
\hline A- & 184 & $21.2 \%$ & $78.8 \%$ & 101 & $23.8 \%$ & $76.2 \%$ \\
\hline $\mathrm{B}+$ & 211 & $25.6 \%$ & $74.4 \%$ & 104 & $26.0 \%$ & $74.0 \%$ \\
\hline B & 185 & $43.8 \%$ & $56.2 \%$ & 100 & $42.0 \%$ & $58.0 \%$ \\
\hline B- & 136 & $64.0 \%$ & $36.0 \%$ & 69 & $44.9 \%$ & $55.1 \%$ \\
\hline $\mathrm{C}+$ & 59 & $62.7 \%$ & $37.3 \%$ & 53 & $60.4 \%$ & $39.6 \%$ \\
\hline $\mathrm{C}$ & 61 & $78.7 \%$ & $21.3 \%$ & 18 & $77.8 \%$ & $22.2 \%$ \\
\hline $\mathrm{D}$ & 70 & $58.6 \%$ & $41.4 \%$ & 27 & $63.0 \%$ & $37.0 \%$ \\
\hline
\end{tabular}

When do you mostly use social media for academic purpose?

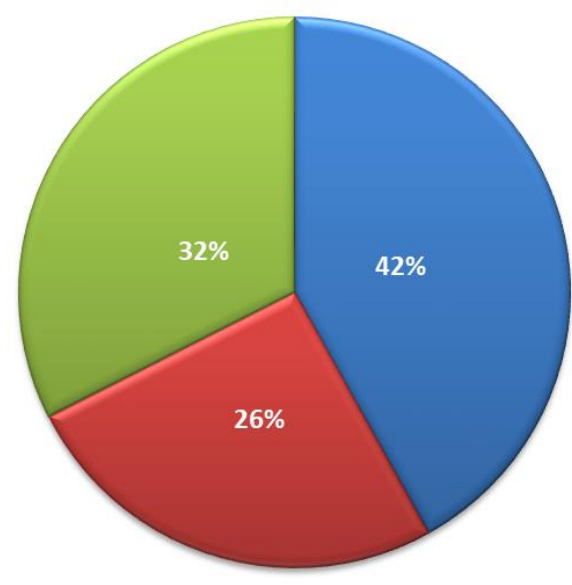

$\square$ Before Exam $\square$ Everyday $\square$ Every Week

Fig. 3. Social Media use for Academic Purpose.

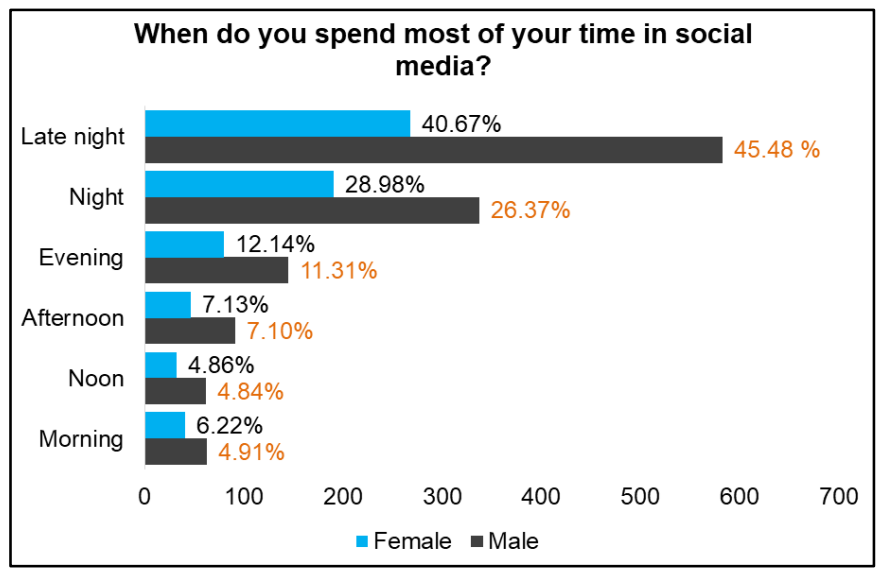

Fig. 4. When Students Spend Time in Social Media Mostly?

$28.98 \%$ female and $26.37 \%$ male students answered that they spend most of their time on social media at night. Also ' $12.14 \%$ female and $11.31 \%$ male', ' $7.13 \%$ female and $7.10 \%$ male', ' $4.86 \%$ female and $4.84 \%$ male' and ' $6.22 \%$ female and $4.91 \%$ male' students prefer spending most of their time in social media at evening, afternoon, noon and morning respectively.

\section{CAUSe IdENTIFICATION OF AdVERSE EFFECTS OF SOCIAL MEDIA}

Some significant factors that negatively impact the academic performance of learners are recognized according to the results of the present research and substantial literature review. All of these factors are directly linked to the excessive use of social media. Fig. 5 represents how SNS impacts on students' academic performance. Excessive SNS use is responsible for aggressive behaviors, lower self-esteem, anxiety, depression, lack of concentration, poor sleep quality, loneliness, fear of missing out, etc. All those factors impact students' academic results badly.

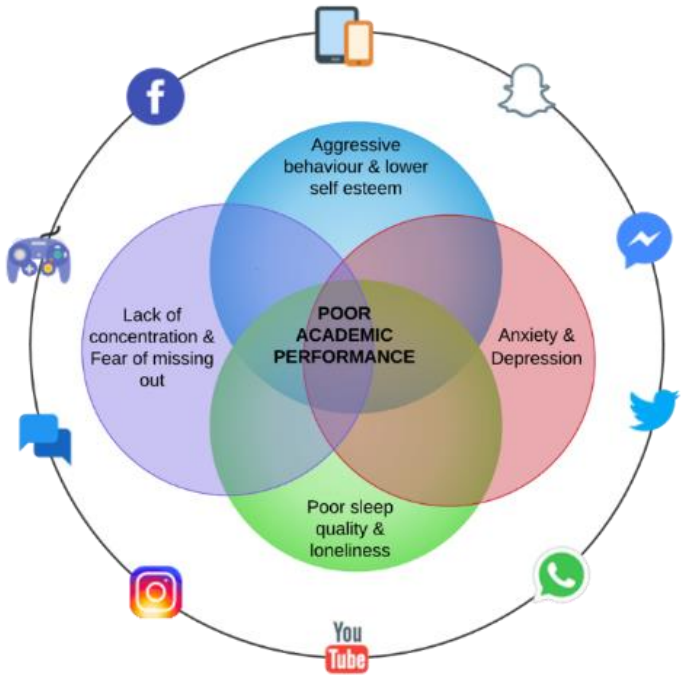

Fig. 5. Factors behind Poor Academic Performance.

\section{SOLUTION}

\section{A. Related Android Application Review}

Currently, more than 65 social networking sites are available in this world. Among them, 15 to 20 sites are dominating the world. However, there are few apps designed to efficiently regulate social networking sites. Among them, very few are popular and at the same time, they have some common features. The primary objective of these apps is to enable users to monitor their phone time and minimize distraction. These application helps to break users' habits, avoid distracting themselves by their phone, or just offer themselves some time off. As a result, users become able to lead an addiction-free life. This application has some unique features (parental control on SNS) along with the existing features that are different from other applications. At the same time, long research has conducted before designing this application which makes this app to be effective as much as possible. Concurrently this application is specially made for students. From this view, this app is unique to focus on students more than others. Table VI shows that all previous applications are made for all general users. Any of the applications are not specially made for students. However, our proposed are specially made for students to use. 
TABLE. VI. EXISTING RELATED APPLICATION's DETAILS

\begin{tabular}{|c|c|c|c|c|}
\hline Serial & App name & Features & Target audience & Ref. \\
\hline 1 & AntiSocial: phone addiction & $\begin{array}{l}\text { 1. Keep tracking on phone unlocking time } \\
\text { 2.Track daily phone usage time } \\
\text { 3.Reporting daily and weekly view of user's app } \\
\text { usage } \\
\text { 4. Comparative discussion with others } \\
\text { 5. In-depth signature scoring system } \\
\text { 6. Try to break user's app addiction habit } \\
\text { 7. } 3 \text { optional blocking modes which help individual to } \\
\text { control phone use, block apps etc. }\end{array}$ & All general users & {$[23]$} \\
\hline 2 & $\begin{array}{l}\text { AppBlock - Stay Focused } \\
\text { (Beat Phone Addiction) }\end{array}$ & $\begin{array}{l}\text { 1. Block application } \\
\text { 2. Select how long user want to spend in a particular } \\
\text { app in a day } \\
\text { 3. Highest } 15 \text { minutes during working hours } \\
\text { 4. Block notifications } \\
\text { 5. Use a timer and activate profiles } \\
\text { 6. Protect AppBlock application with a PIN code } \\
\text { 7. List of blocked notifications } \\
\text { 8. Profile lock } \\
\text { 9. Strict Mode to lock user's AppBlock settings }\end{array}$ & All general users & [24] \\
\hline 3 & $\begin{array}{l}\text { Stay Focused - App Block } \\
\text { (Control Phone Addiction) }\end{array}$ & $\begin{array}{l}\text { 1.Block apps } \\
\text { 2. Block apps at a specified time interval } \\
\text { 3. Track daily time spent } \\
\text { 4.Quick Play Pause } \\
\text { 5. Block notifications } \\
\text { off time } \\
\text { 6. App usage history } \\
\text { 7. App time spent } \\
\text { 8. Check phone history } \\
\text { 9. Activity history }\end{array}$ & All general users & {$[25]$} \\
\hline 4 & OFFTIME - Distraction Free & $\begin{array}{l}\text { 1. Block calls, texts, and notifications } \\
\text { 2. Restrict user's access to apps and internet } \\
\text { 3. Limit phone usage } \\
\text { 4. Use profiles that fit your needs } \\
\text { 5. Track phone and app usage, get analytics }\end{array}$ & All general users & [26] \\
\hline 5 & $\begin{array}{l}\text { AppDetox - App Blocker for } \\
\text { Digital Detox }\end{array}$ & $\begin{array}{l}\text { 1. Calm down users mobile app usage } \\
\text { 2. Set user's own rules for apps to detox from heavy } \\
\text { usage } \\
\text { 3. Stop procrastinating and pubbing. } \\
\text { 4. Lock apps with app-locker. } \\
\text { 5. Remind to take a break and stop heavy app usage. } \\
\text { 6. Keep track of violations in a log }\end{array}$ & All general users & [27] \\
\hline
\end{tabular}

\section{B. Implementation of Android Application}

Finding effective solutions against the adverse effects of social media and develop an android based application to minimize the engagement between students and SNS were the key objects of the current study. An android based framework has been proposed and partially implemented to acquire the desired goal. The proposed framework, named Social Media Tracker (SMT), has been illustrated in Fig. 6. The overall framework was split into three phases (User Authentication, Background Activities, and Foreground Activities). In Back End, both real-time (firebase) and local time (SQLite) database were used to keep the data save. Fig. 7 represents the application diagram which provides a high-level graphical view (Front End) of the overall process of the application.

A starting page (see Fig. 8) will appear at the beginning of the installation of this application and at the same time, users will able to see the usage access of this app as shown in Fig. 9. Users must need to read the terms and conditions (see Fig. 11) before continuing the further steps. They need to explain when establishing a new account if they want parental control on or off (see Fig. 10). If a user permits parental control, he/she has to finish the process of signing up (see Fig. 6); otherwise, the user can just skip this feature. If the registration method is successful, an email will be sent to the parent's email address for verification. In order to monitor children's activities (see Fig. 6), parents need to install this application to parent's android device. After verification, a parent will be able to see (usage time of SNS and other applications) and monitor (Check time limit, set maximum usage limit for SNS) the activities of children from parent's device (see Fig. 14, Fig. 15, Fig. 16 and Fig. 17). If children cross the time limit for any application, a warning message will be appeared to children's devices (see Fig. 13). At the same time, children will not be able to set time limits for SNS while parental control is on (see Fig. 12). But if the user skips parental control during the authentication stage, they will inspect their own activities and set a maximum time limit for any application running on their Android device (see Fig. 6). 


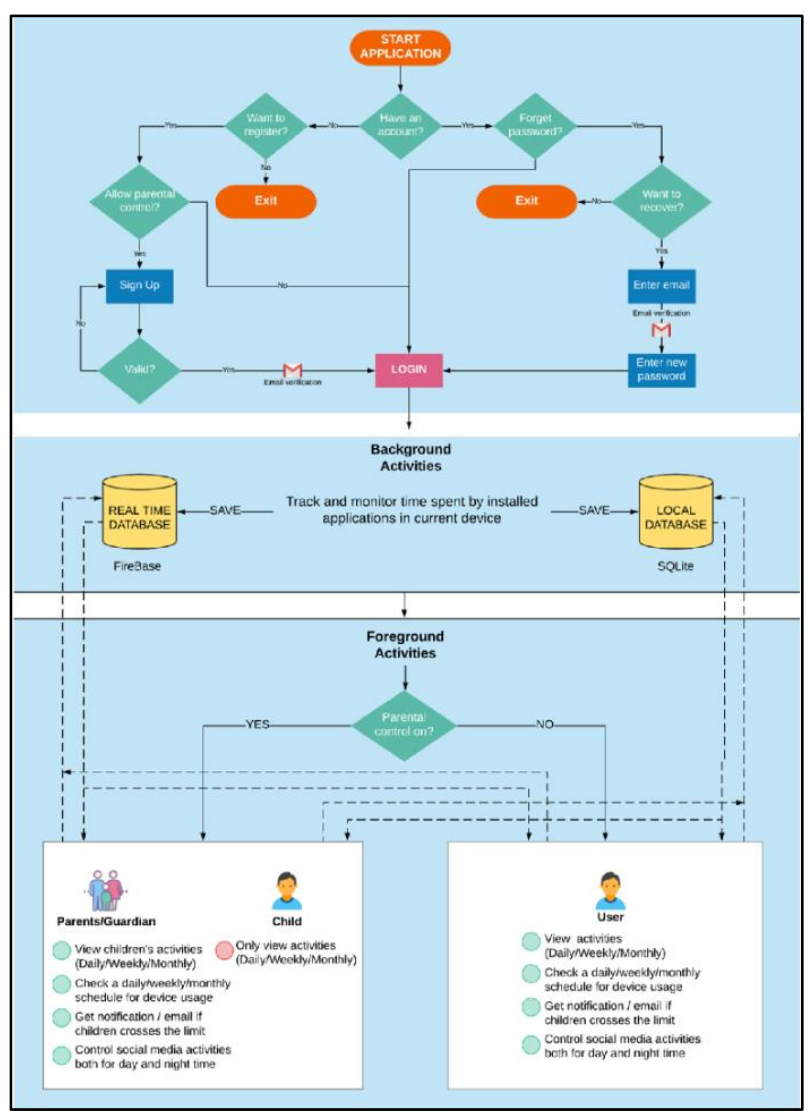

Fig. 6. Proposed Framework (SMT).

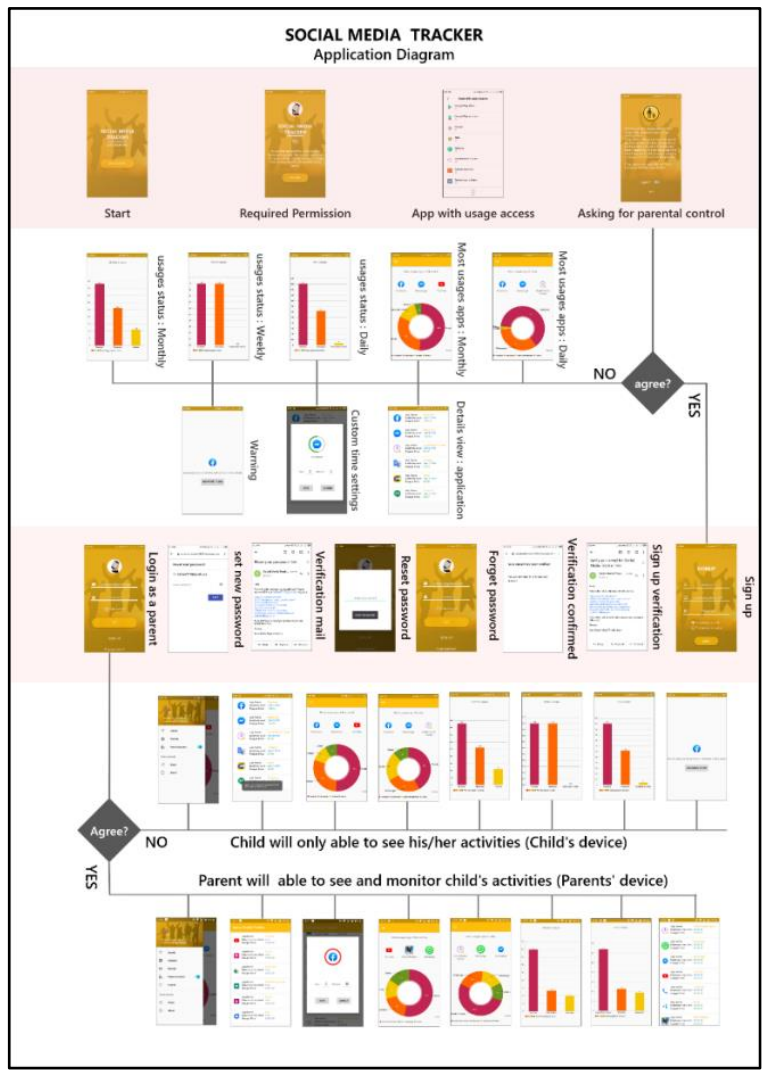

Fig. 7. Application Diagram of SMT.

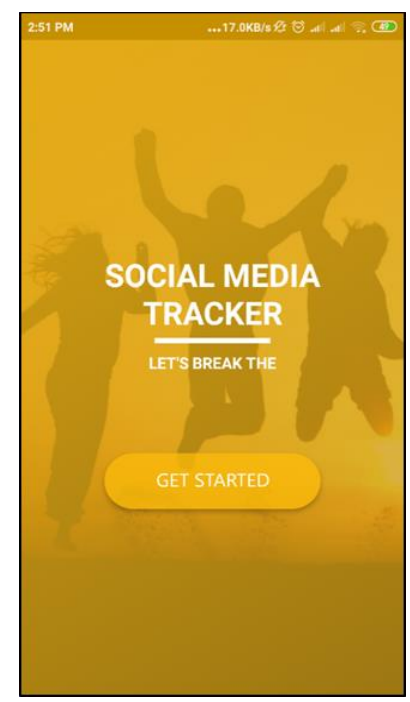

Fig. 8. Start Page.

\begin{tabular}{|c|c|}
\hline 2:52 PM & $\ldots 61.2 \mathrm{~KB} / \mathrm{s} \&$ \& \\
\hline$<$ & Apps with usage access \\
\hline$>$ & $\begin{array}{l}\text { Google Play Store } \\
\text { On }\end{array}$ \\
\hline$\dot{\lambda}$ & $\begin{array}{l}\text { Google Play services } \\
\text { On }\end{array}$ \\
\hline G & $\begin{array}{l}\text { Google } \\
\text { On }\end{array}$ \\
\hline 용 & $\begin{array}{l}\text { msa } \\
\text { on }\end{array}$ \\
\hline 4 & $\begin{array}{l}\text { Security } \\
\text { on }\end{array}$ \\
\hline (A) & $\begin{array}{l}\text { Social Media Tracker } \\
\text { Off }\end{array}$ \\
\hline 보 & $\begin{array}{l}\text { System launcher } \\
\text { On }\end{array}$ \\
\hline 0 & $\begin{array}{l}\text { System app updater } \\
\text { on }\end{array}$ \\
\hline & $\bigodot_{\text {More }}$ \\
\hline
\end{tabular}

Fig. 9. Apps with usage Access.

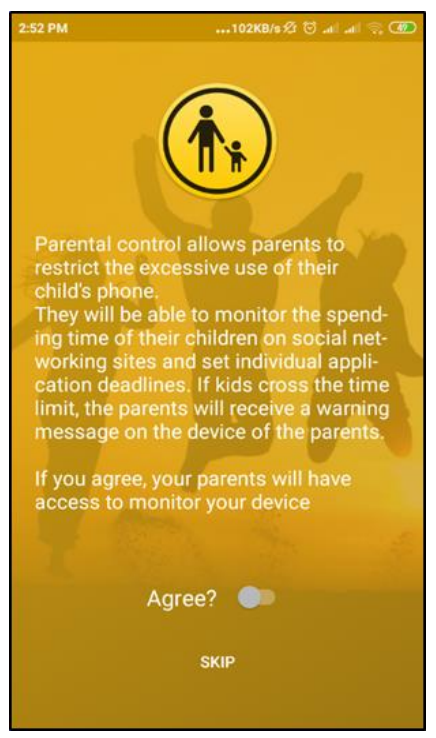

Fig. 10. Parental Control Allow. 


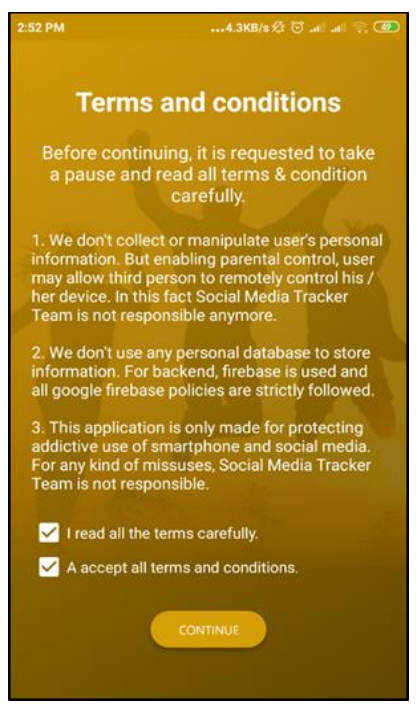

Fig. 11. Terms and Conditions.

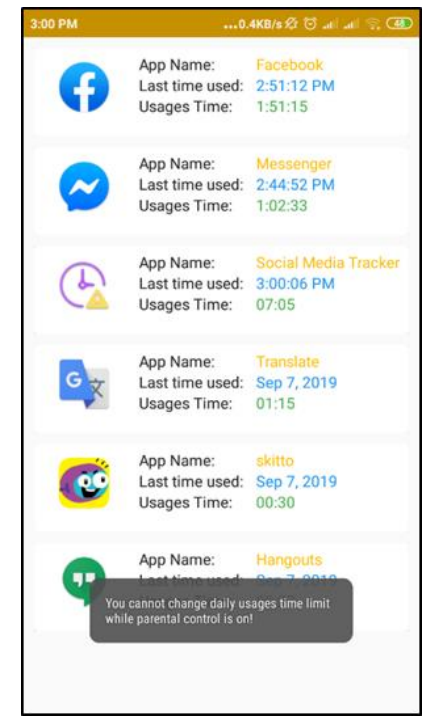

Fig. 12. Children is Notable to Change.

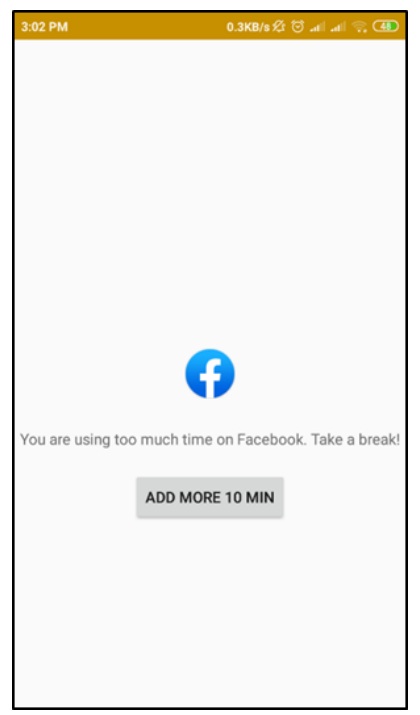

Fig. 13. Warning.

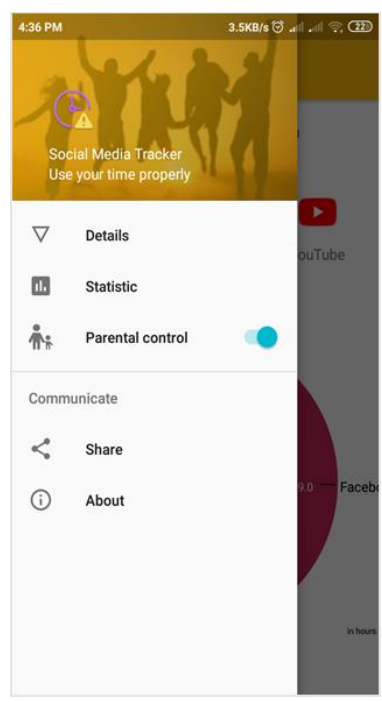

Fig. 14. Child's Activities.

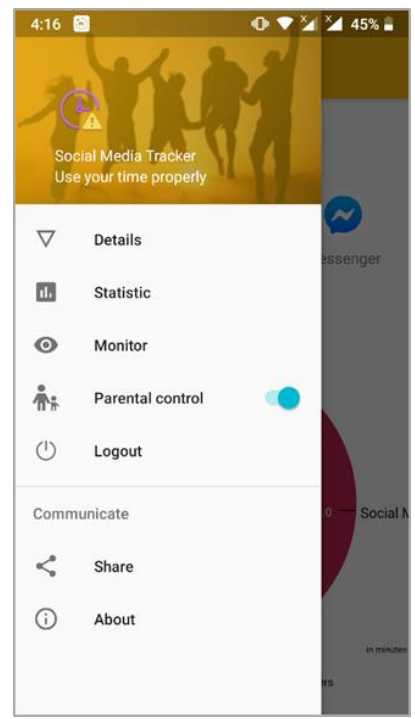

Fig. 15. Parents' Activities

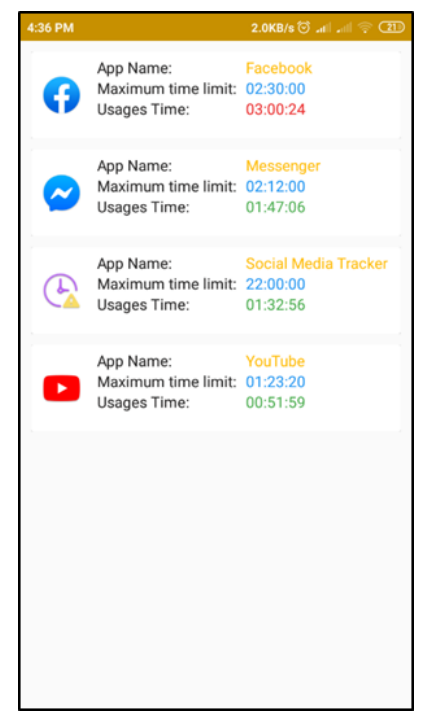

Fig. 16. Childs' Device's usage Time. 


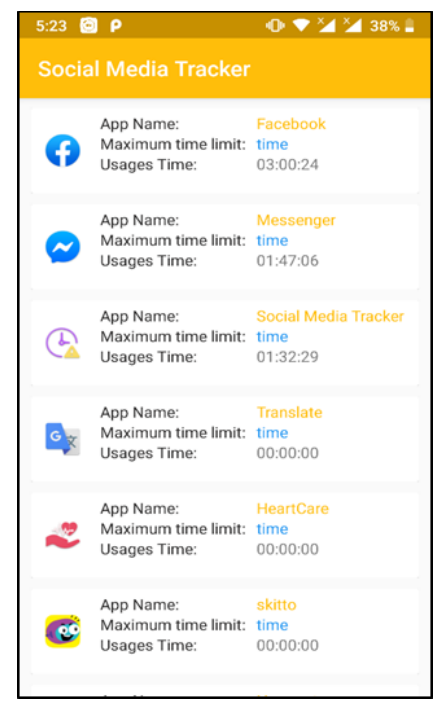

Fig. 17. Monitoring Child by Parents.

\section{RESULTS AND COMPARATIVE DISCUSSION}

SNS is becoming the most significant means of communication. Students use social media both for academic and non-academic purposes. Recently, several studies reported $[5,7,9,10,3]$ the negative impacts of social media on student's academic outcomes. Engaging in social media for a longer period of time plays an important role to be excessively addictive. The main aim of the research was to find out how adverse effects of social media negatively impacts on the educational outcome of the students and to introduce an effective solution to minimize this problem. We attempted to investigate the correlation between social media spending time and academic performance among students using Regression and correlation analysis. Result shows that spending time on social media and academic outcome of students are strongly negatively correlated both for male $(\mathrm{b} 1=-0.1401, \mathrm{R}$ square $=$ 0.519 , Adjusted $\mathrm{R}$ Square $=0.518$, Spearman $=-0.747$, Pearson $r=-0.720$, Kendalltau $=-0.595$ and Point Biserial $=-$ 0.720 .) and female $(\mathrm{b} 1=-0.135, \mathrm{R}$ square $=0.563$, Adjusted $\mathrm{R}$ Square $=0.5626$, Spearman $=-0.787$, Pearson $\mathrm{r}=-0.751$, Kendalltau $=-0.635$ and Point Biserial $=-0.751$ ). Our findings demonstrate that male students spend an average of 4.74 hours per day on social media and female students spend an average of 4.64 hours per day. The study also reveals that learners who spent less time in social media had excellent SGPA and those who engaged for a longer period in social media have achieved poor SGPA (see Table I). This clearly proves that spending excessive time in social media negatively impacts on the academic result. We also attempted to comprehend the reason for the adverse correlation. Our finding indicates that during class time a big percentage of students $(35.05 \%)$ use social media. It can be distracting on the way of learning. As a consequence, instead of focusing on the class, their concentration diverts into non-academic activities. It might be a reason behind bad academic outcomes. Our findings indicate that students having good academic results have a lower tendency to using social media in the classroom than students having bad academic results. It has been noticed that most learners use social media at night $($ male $=26.37 \%$, female $=28.98 \%)$ and late-night $\quad($ male $=45.48 \%$, female $=40.67 \%$ ) which is the key reason behind the poor quality of sleep. It is another reason behind less concentration in the classroom. Since most social media platforms are free, they attempt to get as much attention and time as possible from their users. They pursue the dopamine-driven feedback looping method to capture users' attention to make the platform as addictive as much as possible, which causes poor academic performance, poor sleep quality, anxiety, lack of concentration, waste of time etc. As students unconsciously waste a lot of time in SNS, it negatively impacts their academic performances. Previous studies have shown (see Table VII) that heavy use of SNS has several adverse effects on both the academic and mental health of learners. However, the lack of clear evidence and real rationalization makes the whole thing blurry. At the same time, previous studies did not introduce (see Table VII and Table VI) any significant preventive measures to counter the excessive use of SNS, particularly for students. To cover this gap the current study has proposed and partially implemented an android based application SMT to reduce the engagement students and SNS. Along with adult students, guardians can also use this application to monitor and regulate their children's activities. As a result, this application ensures to protect students from the over-use of SNS and help them not to be addictive to SNS.

TABLE. VII. Summary OF The PREVIOUS StUdies

\begin{tabular}{|l|l|l|l|l|l|l|l|}
\hline Year & Context & Sample & Age & Country & $\begin{array}{l}\text { Research } \\
\text { Objective }\end{array}$ & $\begin{array}{l}\text { Research } \\
\text { findings } \\
\text { preventive } \\
\text { measures? }\end{array}$ \\
\hline $\mathbf{2 0 1 8}$ & SM & 2698 & $12-18$ & India & $\begin{array}{l}\text { To assess the empirical } \\
\text { relationships between } \\
\text { psychosocial well-being and } \\
\text { fatigue in social media. }\end{array}$ & $\begin{array}{l}\text { Compulsive media use } \\
\text { significantly triggered social } \\
\text { media fatigue, resulting in } \\
\text { anxiety and depression }\end{array}$ & No \\
\hline $\mathbf{2 0 1 7}$ & SM & 226 & $14-17$ & United States & $\begin{array}{l}\text { To investigate reports of } \\
\text { adolescents and parents regarding } \\
\text { the use of social media of } \\
\text { adolescents and its relationship to } \\
\text { psychosocial adjustment. }\end{array}$ & $\begin{array}{l}\text { Because of using social media, } \\
\text { adolescents experienced } \\
\text { anxiety, depressive symptoms } \\
\text { and high levels of FoMO }\end{array}$ & No \\
\hline
\end{tabular}




\begin{tabular}{|c|c|c|c|c|c|c|c|c|}
\hline 2018 & SPA & 265 & $21.04 \pm 2.63$ & Turkey & $\begin{array}{l}\text { Identify the level of smartphone } \\
\text { addiction among learners from } \\
\text { different departments at a } \\
\text { university foundation }\end{array}$ & $\begin{array}{l}\text { Usages of the smartphone are } \\
\text { related to lower GPA. } \\
\text { Concurrently, potential risks } \\
\text { are found in the case of } \\
\text { smartphone addiction. }\end{array}$ & No & [30] \\
\hline 2017 & $\begin{array}{l}\text { SM \& } \\
\text { SMM }\end{array}$ & 348 & $17-28$ & Hong Kong & $\begin{array}{l}\text { This research examined whether } \\
\text { and how academic achievement } \\
\text { among university learners is } \\
\text { predicted by these two behaviors } \\
\text { (heavy use of social media and } \\
\text { multitasking social media). }\end{array}$ & $\begin{array}{l}\text { Findings show that using } \\
\text { social media for educational } \\
\text { reasons was not an important } \\
\text { predictor of academic } \\
\text { performance as measured by } \\
\text { the cumulative grade point } \\
\text { average, whereas using social } \\
\text { media for non-academic } \\
\text { reasons and multitasking social } \\
\text { media substantially predicted } \\
\text { academic performance. }\end{array}$ & No & [31] \\
\hline 2016 & SPA & 490 & $14 \pm 0.89$ & South Korea & $\begin{array}{l}\text { To examine the incidence of } \\
\text { young adolescents at risk of SPA } \\
\text { and SPA-related psychological } \\
\text { variables. }\end{array}$ & $\begin{array}{l}26.61 \text { percent of adolescents } \\
\text { experienced considerably } \\
\text { higher rates of behavioral and } \\
\text { emotional problems, reduced } \\
\text { self-esteem and poorer } \\
\text { communication with their } \\
\text { parents and SPA is related } \\
\text { with aggressive behavior. }\end{array}$ & No & {$[32]$} \\
\hline 2017 & SM & 1787 & $19-32$ & United States & $\begin{array}{l}\text { This study aimed at evaluating } \\
\text { multivariable associations in } \\
\text { young adults in the United States } \\
\text { between the uses of different SM } \\
\text { platforms and self-reporting of } \\
\text { depression and anxiety. }\end{array}$ & $\begin{array}{l}\text { The use of various SM } \\
\text { platforms is connected with } \\
\text { depression and anxiety } \\
\text { symptoms separately. These } \\
\text { associations are powerful } \\
\text { enough for clinicians to ask } \\
\text { people with depression and } \\
\text { anxiety about the use of } \\
\text { various platforms }\end{array}$ & No & [33] \\
\hline 2015 & SNS & 753 & Mage $=14.1$ & Canada & $\begin{array}{l}\text { This research examined the } \\
\text { connection between spending time } \\
\text { on SNS and unmet need for } \\
\text { mental health assistance, bad self- } \\
\text { reported mental health, and reports } \\
\text { of psychological distress and } \\
\text { suicidal thinking. }\end{array}$ & $\begin{array}{l}\text { Daily more than } 2 \text { hours of } \\
\text { SNS use is correlated } \\
\text { separately with bad mental } \\
\text { health self-rating and elevated } \\
\text { psychological distress and } \\
\text { suicidal ideation experiences. } \\
\text { Findings also reveal that } \\
\text { excessive SNSs may be the } \\
\text { reason for bad mental health. }\end{array}$ & No & [34] \\
\hline 2019 & SM & 232 & $\begin{array}{l}\text { Mage }= \\
19.18\end{array}$ & China & $\begin{array}{l}\text { This study examined the } \\
\text { relationships of SM addiction to } \\
\text { mental health and academic } \\
\text { performance of college learners } \\
\text { by exploring the role of self- } \\
\text { esteem as a mediator for } \\
\text { relationships, and further } \\
\text { evaluated the efficacy of an } \\
\text { intervention in decreasing } \\
\text { addiction to social media and its } \\
\text { potential negative results. }\end{array}$ & $\begin{array}{l}\text { The study discovered that } \\
\text { SM addiction was negatively } \\
\text { correlated with the mental } \\
\text { health and academic } \\
\text { performance of the learners } \\
\text { and that self-esteem } \\
\text { mediated the relationship } \\
\text { between SM addiction and } \\
\text { mental health. }\end{array}$ & No & [35] \\
\hline 2018 & SNS & 180 & $16-17$ & Surabaya & $\begin{array}{l}\text { The purpose of this research was } \\
\text { to clarify the correlations between } \\
\text { family support, academic stress, } \\
\text { use of social network site (SNS) } \\
\text { and insomnia in adolescents }\end{array}$ & $\begin{array}{l}\text { Major variables connected } \\
\text { with adolescent insomnia are } \\
\text { the reasons for SNS use, } \\
\text { duration of SNS use, and } \\
\text { academic stress. In order to } \\
\text { decrease insomnia, these } \\
\text { elements should be integrated } \\
\text { into multi-component } \\
\text { instructional interventions } \\
\text { aimed at both adolescents and } \\
\text { parents. }\end{array}$ & No & [36] \\
\hline
\end{tabular}




\section{CONCLUSION}

Interactive architecture and addictive functionality have made SNS a vital part of life. Excessive use of social media, particularly for students, has nowadays become a global problem. Addictive use of SNS adversely affects the students' academic performance as well as mental health. The current study found a significant negative correlation between the time spent on social media by students and their academic outcomes. Our investigation shows that students who spend an enormous amount of time in SM achieve poor academic performance compared to those who spend less time in SM. The findings of this study also revealed that students usually use social media for academic purposes just prior to the exam and use SM as an entertainment tool for most of their time. Concurrently, students generally prefer using SM at late night which is responsible for their poor quality of sleep. To minimize the engagement between students and SNS (Social Networking Sites), an Android based application framework called SMT (Social Media Tracker) has been proposed and partially implemented.

\section{REFERENCES}

[1] "Facebook users worldwide 2019 | Statista", Statista, 2019. [Online]. Available: https://www.statista.com/statistics/264810/number-ofmonthly-active-facebook-users-worldwide/. [Accessed: 17- Jun- 2019].

[2] "Twitter: number of active users 2010-2019 | Statista", Statista, 2019. [Online].

[3] "WhatsApp Status daily active users 2019 | Statistic", Statista, 2019. [Online].Available:https://www.statista.com/statistics/730306/whatsappstatus-dau/. [Accessed: 26- Jun- 2019].

[4] [4] W. Lau, "Effects of social media usage and social media multitasking on the academic performance of university students", Computers in Human Behavior, vol. 68, pp. 286-291, 2017. Available: 10.1016/j.chb.2016.11.043.

[5] R. Junco, "Student class standing, Facebook use, and academic performance", Journal of Applied Developmental Psychology, vol. 36, pp. 18-29, 2015. Available: 10.1016/j.appdev.2014.11.001 [Accessed 17 June 2019].

[6] A. Vannucci, K. Flannery and C. Ohannessian, "Social media use and anxiety in emerging adults", Journal of Affective Disorders, vol. 207, pp. 163-166, 2017. Available: 10.1016/j.jad.2016.08.040.

[7] E. Whittaker and R. Kowalski, "Cyberbullying Via Social Media", Journal of School Violence, vol. 14, no. 1, pp. 11-29, 2014. Available: 10.1080/15388220.2014.949377 [Accessed 17 June 2019].

[8] P. Lowry, J. Zhang, C. Wang and M. Siponen, "Why Do Adults Engage in Cyberbullying on Social Media? An Integration of Online Disinhibition and Deindividuation Effects with the Social Structure and Social Learning Model", Information Systems Research, vol. 27, no. 4, pp. 962-986, 2016. Available: 10.1287/isre.2016.0671 [Accessed 17 June 2019].

[9] C. Andreassen, S. Pallesen and M. Griffiths, "The relationship between addictive use of social media, narcissism, and self-esteem: Findings from a large national survey", Addictive Behaviors, vol. 64, pp. 287293, 2017. Available: 10.1016/j.addbeh.2016.03.006.

[10] S. Power, C. Taylor and K. Horton, "Sleepless in school? The social dimensions of young people's bedtime rest and routines", Journal of Youth Studies, vol. 20, no. 8, pp. 945-958, 2017. Available: 10.1080/13676261.2016.1273522 [Accessed 17 June 2019].

[11] J. van Oosten and L. Vandenbosch, "Sexy online self-presentation on social network sites and the willingness to engage in sexting: A comparison of gender and age", Journal of Adolescence, vol. 54, pp. 4250, 2017. Available: 10.1016/j.adolescence.2016.11.006 [Accessed 17 June 2019].

[12] H. Andersson, "Social media is 'deliberately' addictive", BBC News, 2018. [Online]. Available: https://www.bbc.com/news/technology44640959. [Accessed: 17- Jun- 2019].
[13] Abbas, J., Aman, J., Nurunnabi, M. and Bano, S. (2019). The Impact of Social Media on Learning Behavior for Sustainable Education: Evidence of Students from Selected Universities in Pakistan. Sustainability, 11(6), p.1683.

[14] Rostaminezhad, M., Porshafei, H. and Ahamdi, A. (2018). "Can effective study approaches mediate the negative effect of social networking on academic performance?". Education and Information Technologies, 24(1), pp.205-217.

[15] S. Bellur, K. Nowak and K. Hull, "Make it our time: In class multitaskers have lower academic performance", Computers in Human Behavior, vol. 53, pp. 63-70, 2015. Available: 10.1016/j.chb.2015.06. 027 [Accessed 26 June 2019].

[16] A. Flanigan and W. Babchuk, "Social media as academic quicksand: A phenomenological study of student experiences in and out of the classroom", Learning and Individual Differences, vol. 44, pp. 40-45, 2015. Available: 10.1016/j.lindif.2015.11.003.

[17] H. Woods and H. Scott, "\#Sleepyteens: Social media use in adolescence is associated with poor sleep quality, anxiety, depression and low selfesteem", Journal of Adolescence, vol. 51, pp. 41-49, 2016. Available: 10.1016/j.adolescence.2016.05.008.

[18] H. Sampasa-Kanyinga and R. Lewis, "Frequent Use of Social Networking Sites Is Associated with Poor Psychological Functioning Among Children and Adolescents", Cyberpsychology, Behavior, and Social Networking, vol. 18 , no. 7, pp. 380-385, 2015. Available: 10.1089/cyber.2015.0055 [Accessed 27 June 2019].

[19] T. Haynes, "Dopamine, Smartphones \& You: A battle for your time Science in the News", Science in the News, 2018. [Online]. Available: http://sitn.hms.harvard.edu/flash/2018/dopamine-smartphones-battletime/. [Accessed: 28- Jun- 2019].

[20] S. Weinschenk, "Why We're All Addicted to Texts, Twitter and Google", Psychology Today, 2012. [Online]. Available: https://www.psychologytoday.com/intl/blog/brain-wise/201209/whywere-all-addicted-texts-twitter-and-google. [Accessed: 27- Jun- 2019].

[21] "Chamath Palihapitiya, Founder and CEO Social Capital, on Money as an Instrument of Change", YouTube, 2017. [Online]. Available: https://www.youtube.com/watch?v=PMotykw0SIk. [Accessed: 27- Jun2019].

[22] H. Macit, G. Macit and O. Güngör, "SOSYAL MEDYA BAĞIMLILIĞI VE DOPAMIN ODAKLI GERIBILDIRIMM ÜZERINE BIR ARAŞTIRMA", Mehmet Akif Ersoy Üniversitesi İktisadi ve İdari Bilimler Fakültesi Dergisi, pp. 882-897, 2018. Available: 10.30798/makuiibf.435845 [Accessed 27 June 2019].

[23] Play.google.com. (2019). [online] Available at: https://play.google.com /store/apps/details?id=com.goozix.antisocial_personal\&hl=en [Accessed 1 Aug. 2019].

[24] Play.google.com. (2019). [online] Available at: https://play.google.com /store/apps/details?id=cz.mobilesoft.appblock\&hl=en [Accessed 1 Aug. 2019].

[25] Play.google.com. (2019). [online] Available at: https://play.google.com/ store/apps/details?id=com.stayfocused\&hl=en [Accessed 1 Aug. 2019].

[26] Play.google.com. (2019). [online] Available at: https://play.google.com /store/apps/details?id=co.offtime.kit\&hl=en [Accessed 1 Aug. 2019].

[27] Play.google.com. (2019). [online] Available at: https://play.google.com /store/apps/details?id=de.dfki.appdetox\&hl=en [Accessed 1 Aug. 2019].

[28] Dhir, A., Yossatorn, Y., Kaur, P. and Chen, S. (2018). Online social media fatigue and psychological wellbeing-A study of compulsive use, fear of missing out, fatigue, anxiety and depression. International Journal of Information Management, 40, pp.141-152.

[29] Barry, C., Sidoti, C., Briggs, S., Reiter, S. and Lindsey, R. (2017). Adolescent social media use and mental health from adolescent and parent perspectives. Journal of Adolescence, 61, pp.1-11.

[30] Dikeç, G. and Kebapçı, A. (2018). Smartphone Addiction Level among a Group of University Students. Journal of Dependence, 19(1), pp.1-9.

[31] Lau, W. (2017). Effects of social media usage and social media multitasking on the academic performance of university students. Computers in Human Behavior, 68, pp.286-291.

[32] Lee, J., Sung, M., Song, S., Lee, Y., Lee, J., Cho, S., Park, M. and Shin, Y. (2016). Psychological Factors Associated With Smartphone 
Addiction in South Korean Adolescents. The Journal of Early Adolescence, 38(3), pp.288-302.

[33] Primack, B., Shensa, A., Escobar-Viera, C., Barrett, E., Sidani, J., Colditz, J. and James, A. (2017). Use of multiple social media platforms and symptoms of depression and anxiety: A nationally-representative study among U.S. young adults. Computers in Human Behavior, 69, pp.1-9.

[34] Sampasa-Kanyinga, H. and Lewis, R. (2015). Frequent Use of Social Networking Sites Is Associated with Poor Psychological Functioning
Among Children and Adolescents. Cyberpsychology, Behavior, and Social Networking, 18(7), pp.380-385.

[35] Hou, Y., Xiong, D., Jiang, T., Song, L., \& Wang, Q. (2019). Social media addiction: Its impact, mediation, and intervention. Cyberpsychology: Journal of Psychosocial Research on Cyberspace, 13(1), article 4.

[36] Nursalam, N., Octavia, M., Tristiana, R. and Efendi, F. (2018). Association between insomnia and social network site use in Indonesian adolescents. Nursing Forum, 54(2), pp.149-156. 